Title:

Dry friction and wear of self-lubricating carbon-nanotube-containing surfaces

\title{
Authors:
}

Leander Reinert, Michael Varenberg, Frank Mücklich, Sebastian Suárez

This is the accepted manuscript of an article published in Wear (Volume 406-407, 2018, Pages 33-42, DOI: 10.1016/j.wear.2018.03.021).

The version of record is available online at: https://doi.org/10.1016/j.wear.2018.03.021

This manuscript is distributed under the terms and conditions of the Creative Commons License CC BY-NC-ND 4.0 (https://creativecommons.org/licenses/by-nc-nd/4.0/). 


\title{
Dry friction and wear of self-lubricating carbon-nanotube-
}

\section{containing surfaces}

\author{
Leander Reinert ${ }^{1,}$, Michael Varenberg ${ }^{2}$, Frank Mücklich ${ }^{1}$, and Sebastian Suárez ${ }^{1}$ \\ ${ }^{1}$ Department of Materials Science, Saarland University, Campus D3.3, D-66123, Saarbrücken, Germany \\ ${ }^{2}$ George W. Woodruff School of Mechanical Engineering, Georgia Institute of Technology, Atlanta, USA
}

\begin{abstract}
The unfavorable environmental conditions of certain tribological systems, such as operation at high temperatures or under vacuum, set the need to replace liquid with solid lubricants. Multi-Wall-Carbon Nanotubes (MWCNTs) have been emphasized as a very effective solid lubricant. The particles have been used to create self-lubricating materials by acting as reinforcement phase in composites or as solid-lubricant coating that works in conjunction with textured surfaces to prevent the removal of particles from the contact. However, both approaches are restricted to some extent. In the case of composites, the solid lubricant concentration is limited so as not to influence the mechanical stability of the final component. For coated surface structures, the textured surfaces can degrade during the experiment. The present study focuses on the combination of these approaches in order to create enhanced self-lubricating surfaces with MWCNTs as the solid lubricant. A custom-made ring-on-block tribometer is used to study the behavior of laser textured MWCNT-coated and MWCNT-reinforced nickel matrix composites under the conditions of unidirectional sliding in conformal contact. It is shown that the combination of both approaches allows for a maximum 4-fold reduction in friction and a 115-fold reduction in wear rate compared to the reference. Additionally, the lubrication mechanism of the MWCNTs is investigated in more detail and a structural degradation model of the mechanically stressed MWCNTs is proposed. Our results highlight the integrated solution as a suitable approach for self-lubricating surfaces subjected to unidirectional sliding.
\end{abstract}

\section{Keywords}

Self-lubricating; Carbon nanotubes, Solid lubrication, Metal matrix composites; Laser texturing; Coating

\section{Introduction}

In almost every technical system, motion is realized through various types of bearings. Their tribological optimization with respect to the material [1], the surface design [2,3] and the lubrication type [4] is an important task. The effective lubrication of a bearing is often achieved using a liquid lubricant. However, the use of solid instead of liquid lubricants can be advantageous in cases of unfavorable environmental conditions such as high temperatures or vacuum $[5,6]$.

* Corresponding author. Tel/Fax: +49 (681) 302 70544/70502. Permanent address: Campus D3.3, Saarland University, Saarbrücken D-66123, Germany.E-mail address: l.reinert@mx.uni-saarland.de (L.Reinert) 
There is a wide variety of solid lubricants, such as $\mathrm{MoS}_{2}, \mathrm{WS}_{2}$ or graphite [5,6]. However, they also show restrictions with regard to their operational environment [5]. For example, $\mathrm{MoS}_{2}$ is only used in applications working under vacuum or inert gas, since it can react with oxygen in an atmospheric environment and lose its lubrication abilities [5]. In contrast, graphite shows efficient lubrication exclusively under moderate to high relative humidity. In cases of low relative humidity or vacuum, a high coefficient of friction is observed because its lubrication mechanism relies on the intercalation of consecutive graphene layers by water molecules [7].

Recently, Multi-Wall Carbon Nanotubes (MWCNT) have been identified as very promising candidates to reduce friction and wear for a wide span of operational conditions, such as surface roughness, relative humidity, temperature, and environmental pressure [8-17]. Their ability to act as solid lubricant is based on their outstanding material properties and cylindrical shape built from multiple hollow graphitic shells with high aspect ratio $[18-21]$.

There are different theories about the lubrication mechanism of MWCNT. Dickrell et al. showed a frictional anisotropy effect, particularly in case of CNT coatings [22,23]. CNT that are aligned horizontally to a surface show a much lower coefficient of friction than CNT aligned perpendicularly to the surface. It was concluded that CNT possess the ability to efficiently separate the sliding surfaces and are able to slide and/or roll on the surfaces. This theory is backed up by atomic force microscope experiments that measured the lateral forces involved in generating a sliding or a rolling motion of a single MWCNT on a graphitic surface [21]. In continuation of this work, a so called "tank-belt" model describing the CNT rolling motion as similar to that of a deformed chain rolling between two contacting surfaces under shear has been also reported [24,25]. On the other hand, there is also work on fullerene-like nanoparticles used as oil additives, where the authors state that the nanoparticles cannot act as rolling bodies if the observed friction coefficient significantly exceeds that typical for rolling [26]. Interestingly, under high pressure and shear, the strong deformation of the CNT can result in the delamination of flake-like graphitic structures and the formation of carbonaceous layers on the surface, providing low shear strength similar to graphite lubrication [11,27,28]. Aside from experiments, simulations have shown that in the case of high temperatures, a pressure-induced transformation of CNT towards graphite may take place [29]. Due to the promising lubrication effects, CNTs have been used as coatings or reinforcement phases in composites $[8,9,11,16,22,27,28,30]$.

In self-lubricating materials, metal matrix composites are of much interest due to their high technological relevance, the ability to tailor their microstructure and the possibility to incorporate solid lubricants as reinforcement phases [31-34]. For example, it is well known that the microstructures of composites, and thus their mechanical and tribological properties, can be adjusted by varying the type and amount of the reinforcement phase [35-37]. This is mainly attributed to a grain refinement control (pinning effect), which leads to higher strength of the composite. Furthermore, the particles might hinder the dislocation mobility, thus retarding the plastic deformation of the surfaces. Finally, a continuous supply of solid lubricant (i.e. CNT) can be ensured with ongoing wear of the surface, providing constant lubrication $[9,11,30]$. However, the amount of reinforcement phase is limited so as not to affect the mechanical integrity of the sintered composite.

An alternative to increase the amount of solid lubricant in a contact is to have a surface with regular depressions filled with the solid lubricant [10,38-41]. For CNT, this approach has been previously explored using direct laser interference patterning (DLIP) of steel surfaces in combination with a CNT coating produced by electrophoretic deposition (EPD) [10]. It was shown that the duration of the lubrication effect can be extended by a factor of at least five compared to a CNT-coated flat steel surface. This is due to the storage of CNTs in the surface 
depressions, preventing the removal of the CNTs from the contact and enabling a constant supply of solid lubricant.

The present study aims at combining both aforementioned approaches (CNT-reinforced metal matrix composites and laser-textured CNT-coated surfaces) in order to improve the self-lubricating ability of the surface. The study is also driven by the need to understand the lubrication mechanisms of CNTs, so that they can be used as solid lubricant in the most efficient way.

\section{Materials and methods}

\subsection{Composite production}

In this work, MWCNTs having a diameter of 20-85 nm and a length of 5-15 $\mu \mathrm{m}$ were purchased from Graphene Supermarket (USA). In their as-received form, the MWCNTs form agglomerates with a mean size of about 1 $\mathrm{mm}$ in diameter. In order to use the MWCNT as reinforcement phase in nickel matrix composites, they have to be disentangled, which is done using a colloidal dispersion and mixing process. For this process, ethylene glycol is used as a solvent, as it allows for fine and stable dispersions of MWCNTs [30,35,36,42]. Dispersing the nanoparticles in the solvent was done using a shear mixer (Ultra-turrax T-25 by IKA) for 5 min, followed by treatment in an ultrasonic bath (Sonorex Super RK $514 \mathrm{BH}$ by Bandelin, $860 \mathrm{~W}, 35 \mathrm{kHz}$ ) for another $20 \mathrm{~min}$. According to previous studies, this process allows for the best dispersion if particle surface functionalization is avoided and if it does not greatly influence the structural integrity of the particles [36]. Subsequently, Ni dendritic powder (Alfa Aesar, -325 mesh size) is added and mixed with the CNTs dispersed in the solvent using the shear mixer, so as to obtain a concentration of 20 vol.- $\%$ of MWCNTs in the Ni powder. Since Nickel only forms metastable carbides under very specific conditions, it appears to be well suited for the presented study $[42,43]$. After evaporating the solvent in a furnace at $150{ }^{\circ} \mathrm{C}$, the obtained powder is pre-compacted to green pellets with a diameter of $25.4 \mathrm{~mm}$ using a pressure of $420 \mathrm{MPa}$ and sintered in a hot uniaxial press under vacuum and axial pressure of $40 \mathrm{MPa}$ at $750{ }^{\circ} \mathrm{C}$ for 4 hours. The heating and cooling rate is set to $10{ }^{\circ} \mathrm{C} / \mathrm{min}$. Additionally, an unreinforced pure Nickel reference is produced under the same conditions. With the given parameters, a densification of at least $95 \%$ is reached. The sintering parameters have been chosen based on a previously developed model predicting the final microstructure of these composites after sintering [35]. After the densification process, the cylindrical samples are ground flat on both sides and are polished using a diamond slurry containing diamond particles of $3 \mu \mathrm{m}$ in diameter on one side. Subsequently, the polished composites are machined to the dimensions given in Fig. 1 and are cleaned with acetone and isopropanol in an ultrasonic bath in order to remove all surface contaminants. The geometrical shape of a block with teeth is needed in order to allow testing in the ring-on-block tribometer described in section 2.4. 


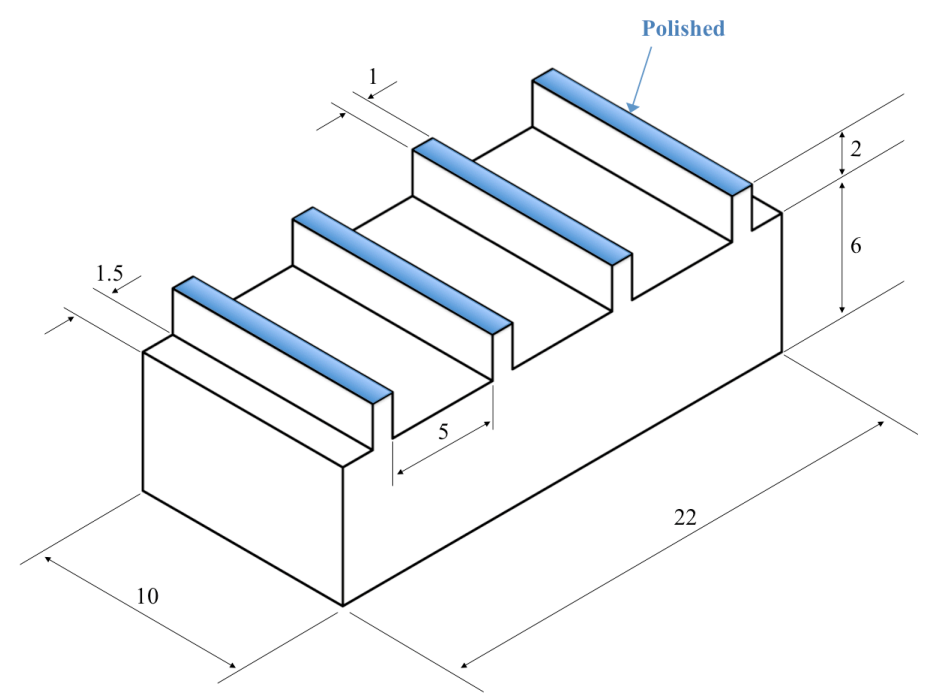

Fig 1: Schematic of a machined sample. The sizes are in $\mathrm{mm}$.

\subsection{Laser texturing}

Direct laser writing (DLW) using a femtosecond pulsed laser system is deployed to create surface depressions by ablation of the surface of CNT-reinforced metal matrix composites. Compared to DLIP, this process allows for the production of larger lubricant-storing surface depressions as well as higher load-bearing capacity. These effects are achieved by avoiding melting, bulging and resolidification of the surface, which can result in increased roughness [44-46]. Accordingly, the teeth of one of the machined 20 vol.-\% of MWCNT-reinforced composite samples are laser textured using a femtosecond pulsed laser system (Spectra-Physics, Ti:Sapphire laser) with a pulse length of $100 \mathrm{fs}$ and a wavelength of $800 \mathrm{~nm}$. The beam (diameter of $8 \mathrm{~mm}$ ) is focused on the sample surface by a lens in order to achieve a laser spot size of $15 \mu \mathrm{m}$. The sample is mounted on a motorized stage, which can perform a two-dimensional linear movement. The processed teeth of the block are moved through the laser beam in a meander-like pattern, thus creating a line-like structure oriented in parallel to the tooth's length. The distance from line-to-line (structural periodicity) is $50 \mu \mathrm{m}$ providing a line width, according to the laser spot size, of $15 \mu \mathrm{m}$. With the laser pulse frequency being $1 \mathrm{kHz}$, the velocity of the stage is chosen to be $6.5 \mathrm{~mm} / \mathrm{s}$, so that the individual laser pulses overlap, and an almost constant structural depth of $1 \mu \mathrm{m}$ can be obtained using a mean laser power of $35 \mathrm{~mW}$. This structure is chosen intentionally, as it only slightly increases the value of the core roughness $R_{k}$ of the surface compared to the reference surface, but still provides the possibility to store a large amount of solid lubricant [45]. Furthermore, large polished areas (width of $35 \mu \mathrm{m}$ ) are provided between the line-like depressions, allowing MWCNTs to perform complex motions and/or to be destroyed at the interface while separating the contacting surfaces. On the other hand, the structural periodicity is chosen not to be too large, so that the tribological contact can be efficiently supplied with MWCNTs stored in the depressions and so that at least 20 line-like depressions get in contact for each individual tooth of the machined sample. 


\subsection{Electrophoretic deposition (EPD)}

With regard to the CNT coatings, EPD has been found most suitable for the present study, being an easily scalable technique for depositing CNT films with a homogeneous thickness on different materials and complex textured surfaces $[10,47]$. It is based on the motion of charged particles in an electric field and the subsequent adhesion/physisorption of these particles onto an electrode substrate in a fluid medium. For the deposition process, the laser-textured block sample is used as anode and a steel block of the same dimensions is used as cathode. The blocks are cleaned stepwise using cyclohexane, acetone and isopropanol in the ultrasonic bath for $10 \mathrm{~min}$, respectively. A dispersion of MWCNTs in acetone with a concentration of $0.25 \mathrm{mg} \mathrm{m}^{-1}$ is prepared using the same dispersion method as described in section 2.1. Hereupon, $3 \mathrm{ml}$ of triethylamine (TEA) are added to the dispersion. This is done in order to add negatively charged $\mathrm{COO}^{-}$surface groups to the outer layer of the MWCNTs, which allows for their deposition on the anode in an electric field [48]. Finally, using a constant voltage of $20 \mathrm{~V}$ for $10 \mathrm{~min}$ in a custom-built deposition cell, the sample is coated with MWCNTs. During this process, a distance of $1.3 \mathrm{~cm}$ between the teeth of the composites and the steel block is kept constant.

\subsection{Tribological testing}

Friction and wear tests were performed on a custom-built ring-on-block tribometer allowing for experiments under conditions of conformal contact with a constant contact area at the steady state regime (schematically presented in Fig. 2). The tribometer consists of a DC-motor-driven precise spindle and a loading frame that is able to rotate as well as to move radially with respect to the spindle's axis. A ring sample is fixed to the spindle's axis.

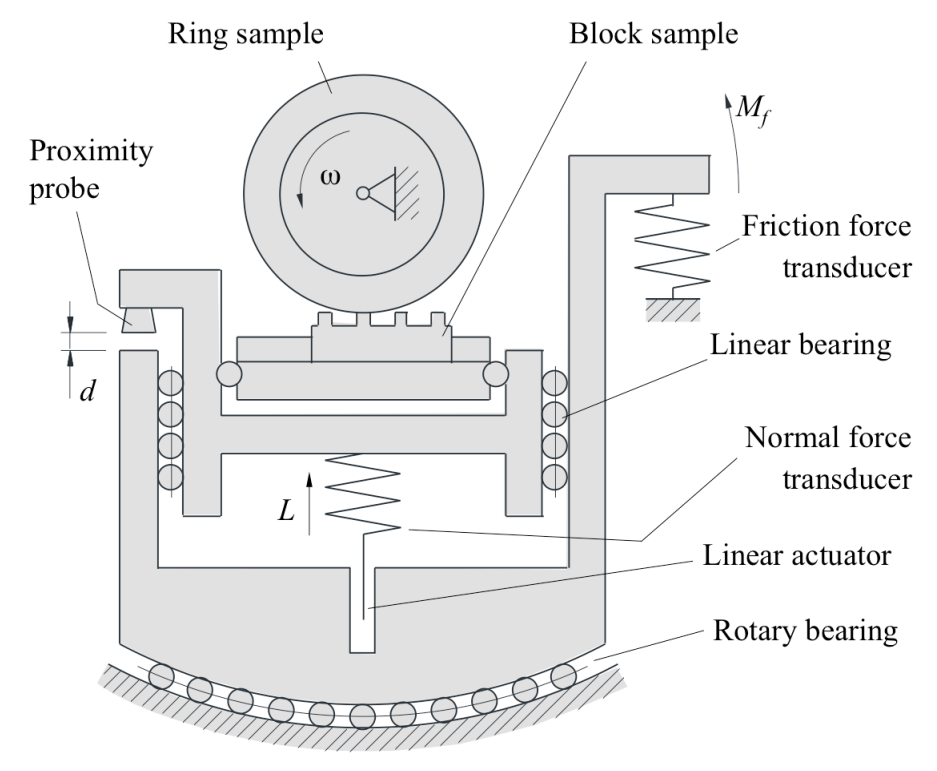

Fig 2: Schematic of the ring-on-block tribometer, which illustrates the working principle of the device tribometer and the installation position of the block sample (depicted in Fig 1). The individual teeth of the block sample have been laser structured and coated with MWCNT.

The ring, made out of mild steel SAE 1045, has an outer diameter of $38 \mathrm{~mm}$, a Vickers hardness of HV 320 and is polished to a surface finish of $R_{a}=0.02 \mu \mathrm{m}$ followed by a cleaning of the surface using acetone and isopropanol. The ring rotates with the speed $\omega=250 \mathrm{rpm}$. Below the ring is the block sample that has four teeth 
of a cross sectional area $\mathrm{S}=20 \mathrm{~mm}^{2}$ each (Fig. 1). The block is fixed to the loading frame and is pressed against the rotating ring under a normal load of $\mathrm{L}=20 \mathrm{~N}$. The normal load is applied by a linear actuator that is controlled in a closed loop using the feedback received from a normal force transducer. The shape and the selfaligning ability of the block sample ensure that, after the running-in is finished, the area of contact between the samples does not change, and the wear volume can be calculated as $\mathrm{V}=\Delta \mathrm{d} \cdot \mathrm{S}$, where $\mathrm{S}$ is the cross sectional area of the tooth brought in contact with the ring, and $\Delta \mathrm{d}$ is the change in distance $\mathrm{d}$ measured by a proximity probe. A friction moment, $\mathrm{M}_{\mathrm{f}}$, that is produced due to the sliding between the ring and the block, pushes the loading frame around the spindle's axis, but its motion is stopped by a force transducer allowing the friction force, F, to be quantified. The effect of friction produced by a rotary bearing is cancelled by proper calibration of the friction force transducer. The experiments were conducted under conditions of $40 \%$ of relative humidity and a temperature of $25^{\circ} \mathrm{C}$.

\subsection{Characterization methods}

The initial state characterization as well as the wear track analysis is performed using a focused ion beam/field emission (dual beam) SEM workstation (FEI Helios NanoLab 600). SEM micrographs and EDS maps are recorded with an accelerating voltage of $5 \mathrm{kV}$ and current of $1.4 \mathrm{nA}$ or $22 \mathrm{nA}$, respectively. The mean grain size and grain orientation of the composites is determined by EBSD with an EDAX TSL detector incorporated in the dual beam microscope. For the EBSD measurement, an accelerating voltage of $20 \mathrm{kV}$ and a current of $22 \mathrm{nA}$ is applied, scanning an area of $400 \times 400 \mu \mathrm{m}^{2}$ with a step size of $0.3 \mu \mathrm{m}$. The acquired data is post-processed using confidence index (CI) standardization in addition to the removal of points with CI below 0.1 . A grain is defined as at least two adjacent points with a maximum misorientation of $5^{\circ}$, beyond which a grain boundary is detected. The grains overlapping with the scan window are excluded from the analysis.

The structural integrity assessment of the MWCNTs is carried out by Raman spectroscopy analysis. For this purpose, an inVia Raman microscope (Renishaw) is used with an excitation wavelength of $532 \mathrm{~nm}(2.33 \mathrm{eV})$, a grating of 2400 lines $\mathrm{mm}^{-1}$, a 50X-objective (numerical aperture: 0.9 ), a spectral resolution of $1.2 \mathrm{~cm}^{-1}$, and a laser power of $0.2 \mathrm{~mW}$. The data acquisition time is $10 \mathrm{~s}$ and each measurement is performed three times for statistical back up. The data is finally processed using a linear baseline subtraction and intensity normalization, followed by a fitting based on the Lorentz function in order to identify the peak positions [49]. Vickers microhardness is measured with a Vickers microindenter (Durascan, Struers) using an indentation force of 0.98 $\mathrm{N}\left(\mathrm{HV}_{0.1}\right)$ and a holding time of $10 \mathrm{~s}$. For each sample, 12 measurements at different spots were conducted and averaged.

\section{Results and discussion}

\subsection{Initial state characterization}

Before tribological testing, the samples were analyzed with regard to the MWCNT distribution in the composite and the microstructure of the Nickel matrix. In Fig. 3, EBSD maps of the unreinforced nickel reference and the reinforced composite, as well as an SEM micrograph of the composite surface, are shown. According to the color-coding of the grain orientations of the reference sample as well as the reinforced composite sample, no preferred grain orientation is found in either case. 

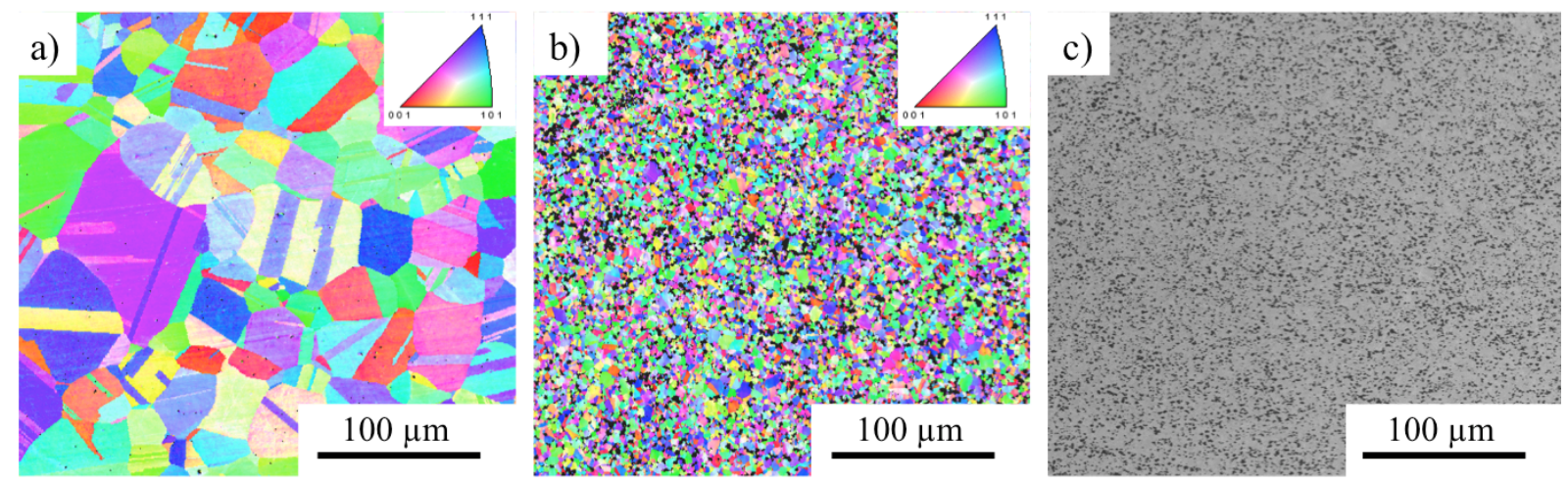

Fig 3: EBSD maps of a) the unreinforced pure Nickel reference and b) the 20 vol.-\% of MWCNT-reinforced composite. The fine and homogeneous distribution of MWCNT agglomerates (black dots) in the nickel matrix (grey) is depicted in c).

Furthermore, it is clearly noticeable that the grain size is drastically reduced from a mean grain size of $29 \pm 19$ $\mu \mathrm{m}$ of the unreinforced reference to a mean grain size of $4.5 \pm 2 \mu \mathrm{m}$ in the case of the reinforced composite. This effect is well-known and is attributed to the Zener pinning effect of CNTs in a metal matrix, resulting in a hindered grain boundary movement during sintering [50]. Due to the hindered grain boundary mobility, the grains are not able to freely grow; thus the mean grain size after sintering is reduced to a significant degree compared to the unreinforced reference. This fact also results in a higher hardness of the reinforced sample due to the Hall-Petch effect of $118 \pm 2 \mathrm{HV}$ of the composite compared to $108 \pm 4 \mathrm{HV}$ of the unreinforced reference [51,52]. As was already reported for CNT-reinforced $\mathrm{Cu}$ matrix composites, with a higher hardness of the composite a lower wear rate is expected [12].

Additionally, one of the MWCNT-reinforced composites is laser textured using DLW with a femtosecond pulsed laser system and subsequently coated with MWCNTs using EPD. The surface of the laser-textured composite surface before and after coating with MWCNT agglomerates is depicted in Fig. $\mathbf{4} \mathbf{a}$ and $\mathbf{b}$. 

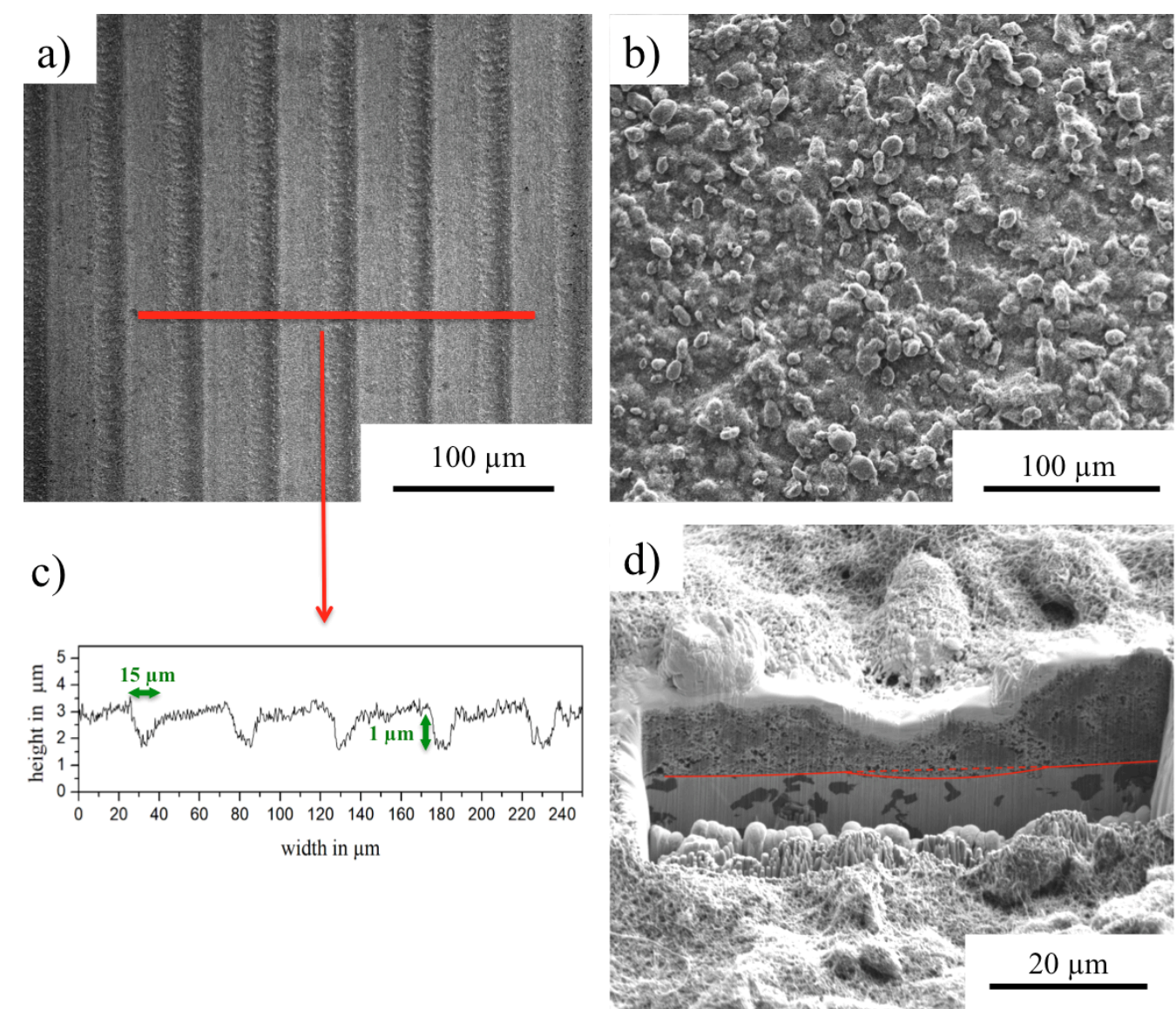

Fig 4: SEM micrograph of the laser-textured composite sample a) before and b) after coating with MWCNTs. In c) a cross-section of the laser-textured surface (marked in red in a)) is depicted by laser scanning microscopy. A SEM micrograph of a FIB cross-section of the laser textured and coated composite is illustrated in d). The surface depression is marked in red for better visibility.

From the cross-section shown in Fig. 4 c, it can be seen that the applied laser texturing provides a structural periodicity of $50 \mu \mathrm{m}$ with a width of $15 \mu \mathrm{m}$ for the line-like depressions. The depth of the depressions is $1 \mu \mathrm{m}$. The coating thickness of $5-10 \mu \mathrm{m}$ is measured using a FIB cross-section in Fig. 4 d. It is evident that the lasermachined depressions are completely covered with the CNT coating.

For tribological experiments, it has to be kept in mind that a DLW process may induce a slightly higher surface oxidation within the irradiated areas [45]. No microstructure changes or phase transformations are expected, as the laser-material interaction in a femtosecond laser system is not long enough to induce thermalization, resulting only in the material ablation. Hence, recrystallization of the surface is excluded [46].

\subsection{Friction and wear}

The unreinforced Ni reference sample (Ref), the MWCNT-reinforced composite sample (Composite) as well as the laser-textured MWCNT-coated reinforced composite (Coated composite) were rubbed under the same conditions. The measurements of coefficient of friction (COF) are shown in Fig. 5. Each curve represents the mean value including the standard deviation of three measurements. The individual experiments were conducted until steady state was reached. The unreinforced reference was only measured for $400 \mathrm{~s}$ due to fast wearing off of the teeth. However, the final COF value of 0.6 correlates well with the steady state COF value reported in the literature for coarse grained Nickel sliding against steel at a relative humidity of $40 \%$ [53]. The running-in of the reference sample is typical for a non-lubricated metal-to-metal contact that has already been analyzed elsewhere 
[54]. The initial raise of the COF from 0.2 to 0.8 can be explained by an increase of the contact area during running-in. As the ring further removes material from the tooth, wear debris accumulates at the interface, leading to formation of a third-body layer that reduces adhesive interaction between the rubbing surfaces and leads to friction reduction. The steady state conditions are reached when the formation of the third-body layer is balanced with escape of wear debris from the interface.

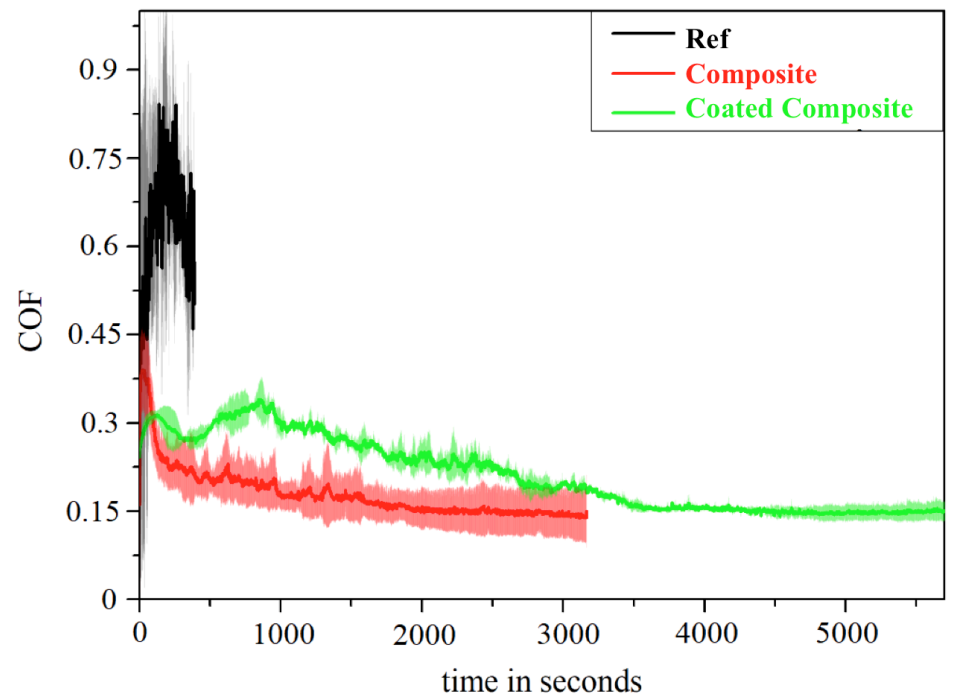

Fig 5: Evolution of the COF of the unreinforced Nickel reference (Ref), the MWCNT-reinforced composite (Composite) and the MWCNT-reinforced composite after laser texturing and MWCNT coating (Coated Composite). Each curve represents the mean value including standard deviation of three measurements.

For the composite sample, the COF curve starts with the same value as for the reference, but it only increases to a maximum value of 0.37 and decreases rapidly within the first $150 \mathrm{~s}$ to a value of 0.22 . After this, it further decreases during the next $2500 \mathrm{~s}$, reaching minimal values of as low as 0.13 at the steady state condition. In the beginning of the experiment, the MWCNTs are embedded in the Nickel matrix, and their contribution to friction is limited, so the COF value is close to that of the reference surface. With the steel ring starting to wear off the block material and to develop a conformal contact with the tooth, the embedded MWCNTs are gradually brought into the contact and start lubricating the system.

A previous study has already shown that the COF of MWCNT-reinforced composites is mainly influenced by the presence of MWCNTs in the contact zone and not by the differences in the composite microstructure [9]. It is assumed that the MWCNTs can easily be dragged out of the surface cavities due to their high aspect ratio $[10,11]$. With on-going wear, more and more MWCNTs are progressively brought into the contact, which further decreases the COF until it reaches the minimal value at the steady state condition. This constant value may be a consequence of the balance between the MWCNTs that are already present in or have just been dragged into the contact from the surface cavities and the MWCNTs that are pushed out of the contact with the wear debris. The lubricating effect of the MWCNTs is attributed to the presence of delaminated/degraded graphitic flakes and the pristine MWCNTs, which are able to slide or roll on the surface. Compared to other studies of the lubricating effect of MWCNTs under the non-conformal contact conditions with the steady state COF of around 0.2 [9-11], the presented COF results are significantly lower. It is believed that the conformal contact conditions support the MWCNTs' ability to separate the surfaces, thus providing higher efficiency in lubricating the system. Since the minimum COF is about 0.13 , while rolling would result in friction coefficients of significantly lower values, 
sliding is considered to be the main type of relative motion [55]. Nonetheless, a partial rolling of the particles cannot be fully excluded.

The laser-textured MWCNT-coated reinforced sample (Coated Composite) also demonstrated a friction reduction compared to the reference surface. However, in contrast to the composite sample, the friction reduction is already seen in the beginning of the experiment with a COF value of $0.25-0.35$. An explanation for this behavior is that MWCNTs are present in the contact zone as free particles right from the start. The COF slightly fluctuates for the first $1000 \mathrm{~s}$, after which it continuously decreases and finally reaches the steady state conditions after $3500 \mathrm{~s}$ with the same COF as the composite sample. Interestingly, although the concentration of MWCNTs on the surface is much higher compared to the composite sample, the friction reduction is less pronounced and is unstable. Most likely, this can be traced back to wear particles, which cannot be efficiently removed from the contact but are stored in the surface depressions. Wear particle agglomerations are thus formed and broken up in a stochastic manner, leading to a slight increase and destabilization of the friction coefficient. Additionally, the initially present thick MWCNT coating is not strong enough to support the load, so the ring sample penetrates it until the block sample is met, only being separated by a very thin layer of MWCNT. The thick coating creates a larger contact area, consequently leading to higher friction. However, with on-going wear, both effects are getting less pronounced. A higher COF due to a phase transformation or a change in mechanical properties of the surfaces induced by laser processing can be excluded, as the laser-material interaction of a femtosecond laser system is based on ablation and not on melting [46]. At the steady state, the laser structures and the MWCNT coating seem to be worn off completely, because the same frictional behavior as for the composite sample is observed. However, in order to get a better understanding of the mechanisms involved, a detailed analysis of wear and the oxidation behavior as well as the evaluation of the structural state of the MWCNT has to be performed.

The tooth wear $\Delta \mathrm{d}$ (see Fig. 2) is given as a function of time in Fig. 6, which also includes the curve slopes representing the wear rate.

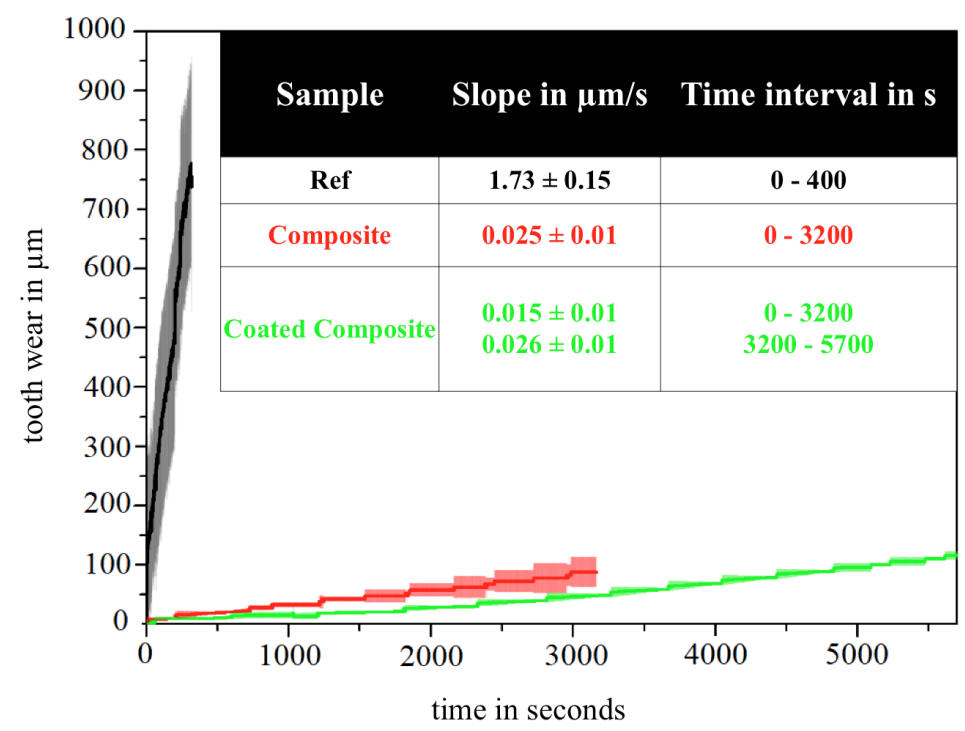

Fig 6: The tooth wear $\Delta d$ as a function of time. The slope of each individual curve represents the wear rate and is included in the graph. Each curve represents the mean value including standard deviation of three measurements 
It is clearly seen that the reference sample is worn much faster than the composite or the coated composite sample. Based on the curve slopes, the wear rate of the composite $(0.025 \pm 0.01 \mu \mathrm{m} / \mathrm{s})$ is 70 times slower than that of the reference $(1.73 \pm 0.15 \mu \mathrm{m} / \mathrm{s})$. For one part, this can be explained with the slightly higher hardness of the composite compared to the reference material. Additionally, the lower mean grain size of the composite material can lead to a more pronounced oxidation, as the grain boundaries would act as diffusion paths for oxygen [56,57]. The formation of a protective oxide layer can lead to a change in wear mechanism and thus to a lower wear rate. Furthermore, the MWCNTs are continuously dragged into the contact, efficiently reducing frictional stress and separating the surfaces, which also contributes to the wear reduction.

In case of the coated composite, two time intervals have to be analyzed separately, as the wear rate changes after $3200 \mathrm{~s}$ of the run-time. For the first $3200 \mathrm{~s}$, the wear rate is $0.015 \pm 0.01 \mu \mathrm{m} / \mathrm{s}$, which corresponds to the reduction of wear by a factor of 115 compared to the reference. After $3200 \mathrm{~s}$, the wear rate slightly increases, meeting the same value as in the composite sample. A straightforward reason for this behavior is the removal of the MWCNT-coated laser structures during the first $3200 \mathrm{~s}$. With the wear rate being almost identical to that of the uncoated composite sample, the behavior of the coated sample is clearly dominated by the substrate material. This also appears reasonable when looking at the COF of the coated composite sample after $3200 \mathrm{~s}$ (Fig. 5), which is similar to the COF of the uncoated composite sample. However, although the COF of the coated composite sample is higher for the first $3200 \mathrm{~s}$, the wear is lower. This can be explained by the fact that the contacting surfaces are more efficiently separated by the higher amount of MWCNTs homogeneously covering the composite surface. With on-going wear, the two contacting surfaces slowly undergo a transition towards a conformal contact. This means that with an increasing wear depth, the laser-induced surface depressions are gradually removed until the tooth contact surface replicates the ring shape. After $3200 \mathrm{~s}$, the supply of the MWCNTs decreases, thus resulting in a higher wear rate. In the following sections, an extensive surface analysis is performed in order to back-up and discuss the above hypotheses in more detail.

\subsection{Characterization of wear}

In Fig. 7, SEM micrographs as well as EDS maps showing the middle of the worn teeth of the reference and composite samples are depicted. From the SEM micrographs, it is evident that the wear mechanisms of the two samples differ significantly. 

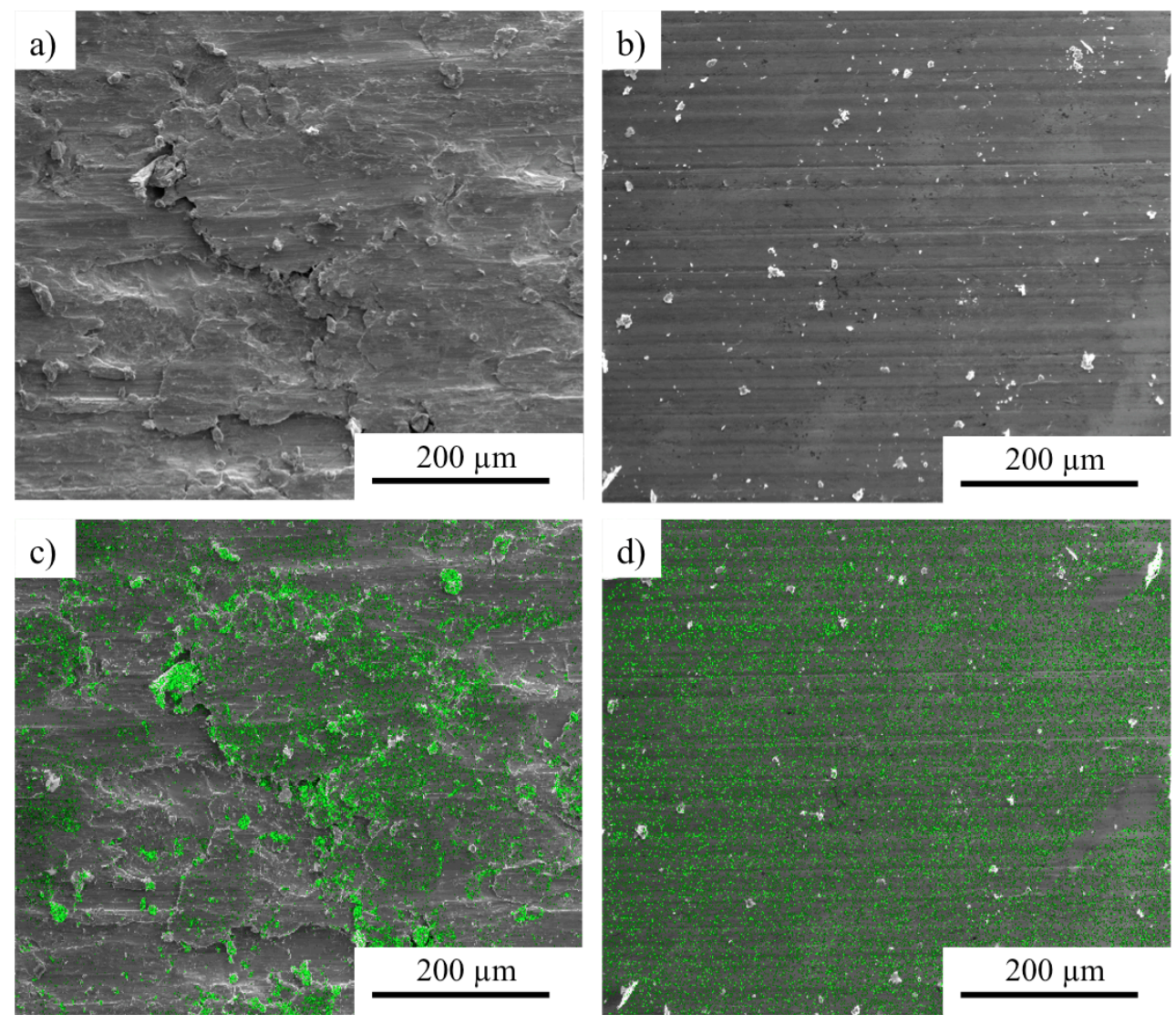

Fig 7: SEM micrographs of the wear tracks in the middle of the tooth for a) the reference and b) the composite surfaces. EDS-maps of oxygen (color green) are superimposed with the SEM micrographs of c) the reference and $d$ ) the composite surfaces.

The reference surface (Fig. 7 a, c) exhibits clear signs of rupture and material transfer with formation of platelike composite plastically-deformed fragments. Large areas of pure Nickel are exposed due to insufficient regeneration of a disrupted protective $\mathrm{NiO}$ surface layer, resulting in the formation and breaking of micro-welds during the experiment and creating a rough surface with a flake-like morphology. A random formation of oxides, which are mostly associated with transferred particles, is observed. Thus, the dominant wear mechanism for the reference sample is the pathological (severe) adhesive wear [58].

In contrast to that, the worn tooth of the composite sample (Fig. $7 \mathbf{b}, \mathbf{d}$ ) exhibits a rather smooth, fully oxidized surface with anisotropic scratch-marks in the sliding direction. The formation of a uniform oxide layer can be explained with the lower grain size in the case of the composite [56,57]. This oxide layer may work as a protective coating, as $\mathrm{NiO}$ is known to act as a high shear strength layer, which is hard to remove [11]. This clearly indicates normal (mild) tribo-chemical wear [58]. Interestingly, the formation of a high shear strength layer would typically result in a higher COF, which is not the case as can be seen in Fig. 5 [11]. This supports the above conclusion that the frictional behavior is dominated by the MWCNTs, which are transferred to the contact area from cavities and slide/roll on the smooth oxidized surface of the composite, efficiently reducing the COF. 


\subsection{Structural integrity of solid lubricant}

Fig. 8 shows a partially worn tooth of the coated composite sample, where the measurement has been stopped during run-in at $1000 \mathrm{~s}$. Three different areas can be noticed.

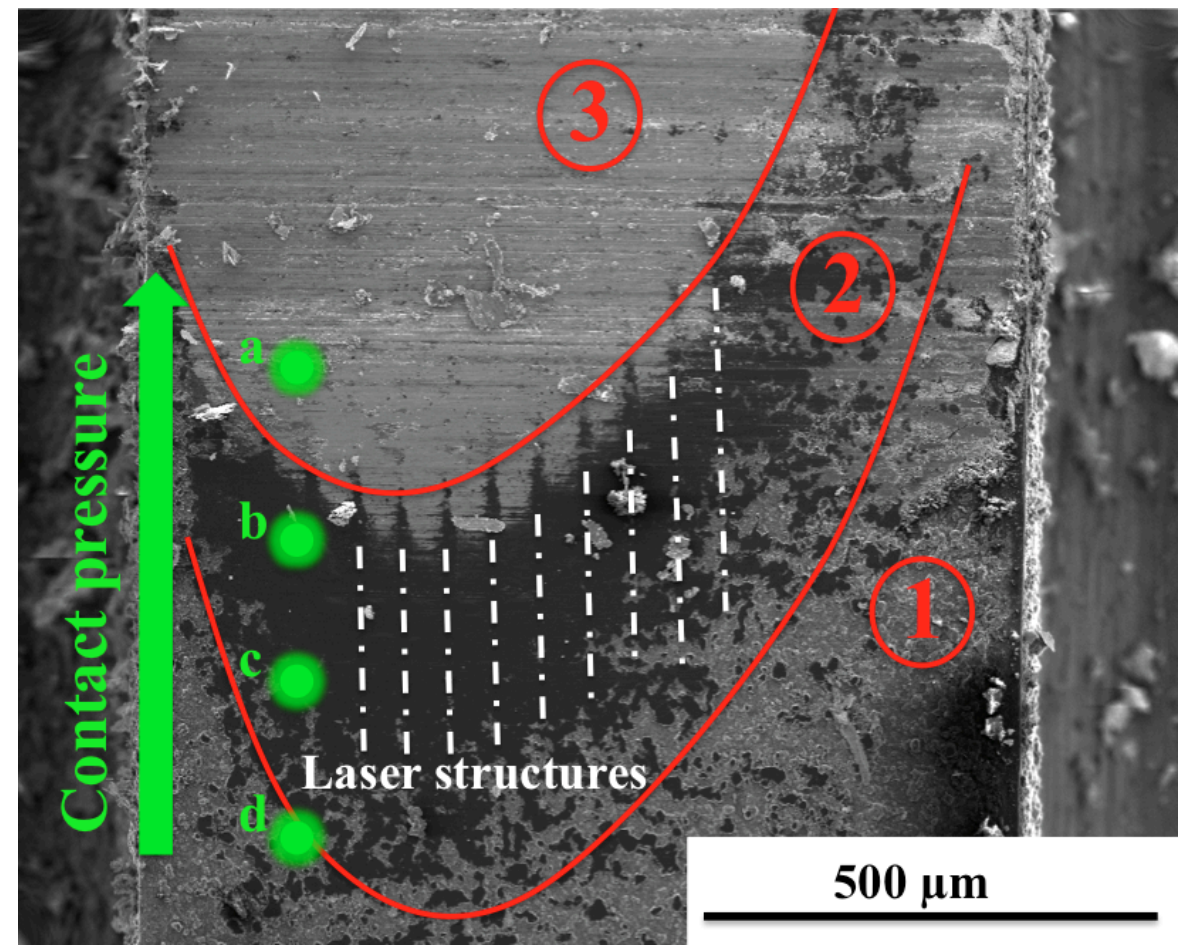

Fig 8: SEM micrograph of a tooth of the coated composite sample after stopping the test at $1000 \mathrm{~s}$. Three different areas of wear, which are separated by red lines for clarity, can be distinguished. Area 1 shows the initial laser-structured and MWCNT-coated surface, whereas area 3 shows the final stage of complete removal of laser structures and CNT coating. Area 2 corresponds to transition between area 1 and area 3, with the laser structures and MWCNT coating still being visible.

Area 1 corresponds to the pristine laser-textured and MWCNT-coated surface, which has not yet been in contact. Area 3 is long in a sliding contact, and, with the laser structures and MWCNT coating being completely removed, it matches the surface appearance of the uncoated composite sample, in which the tribological behavior is determined exclusively by the composite material. For area 2, the darker color of the MWCNT coating indicates that an initial contact has been established. However, the surface is still covered by MWCNTs and the MWCNT-filled line-like laser structures are still observed. Obviously, the tribological system is still in the process of running-in because the contact area does not completely cover the top surface of the tooth. This fact allows for a more detailed analysis of the lubrication mechanism of the particles. Additionally, wear particles are found in area 2, aligning with the remaining laser structures, which supports the statement of an increased and unstable friction coefficient due to wear debris trapping and the subsequent forming and breaking of wear particle agglomerations during running in.

Keeping in mind, that the tribological system undergoes a transition towards a conformal contact condition, it is reasonable to assume a contact pressure gradient, with the pressure increasing from area 1 to area 3 as indicated in Fig. 8. Raman spectroscopy was conducted for these areas. The spots marked as a-d in Fig. 8 are analyzed and the characteristic bands of MWCNTs are compared in order to identify the degradation process of the particles. In Fig. 9, the corresponding Raman spectra are plotted and the characteristic bands are given as D, G and G'. 
Additionally, schematic illustrations are added to the spectra to present the structural degradation model of the MWCNTs found in each contact situation (a-d).

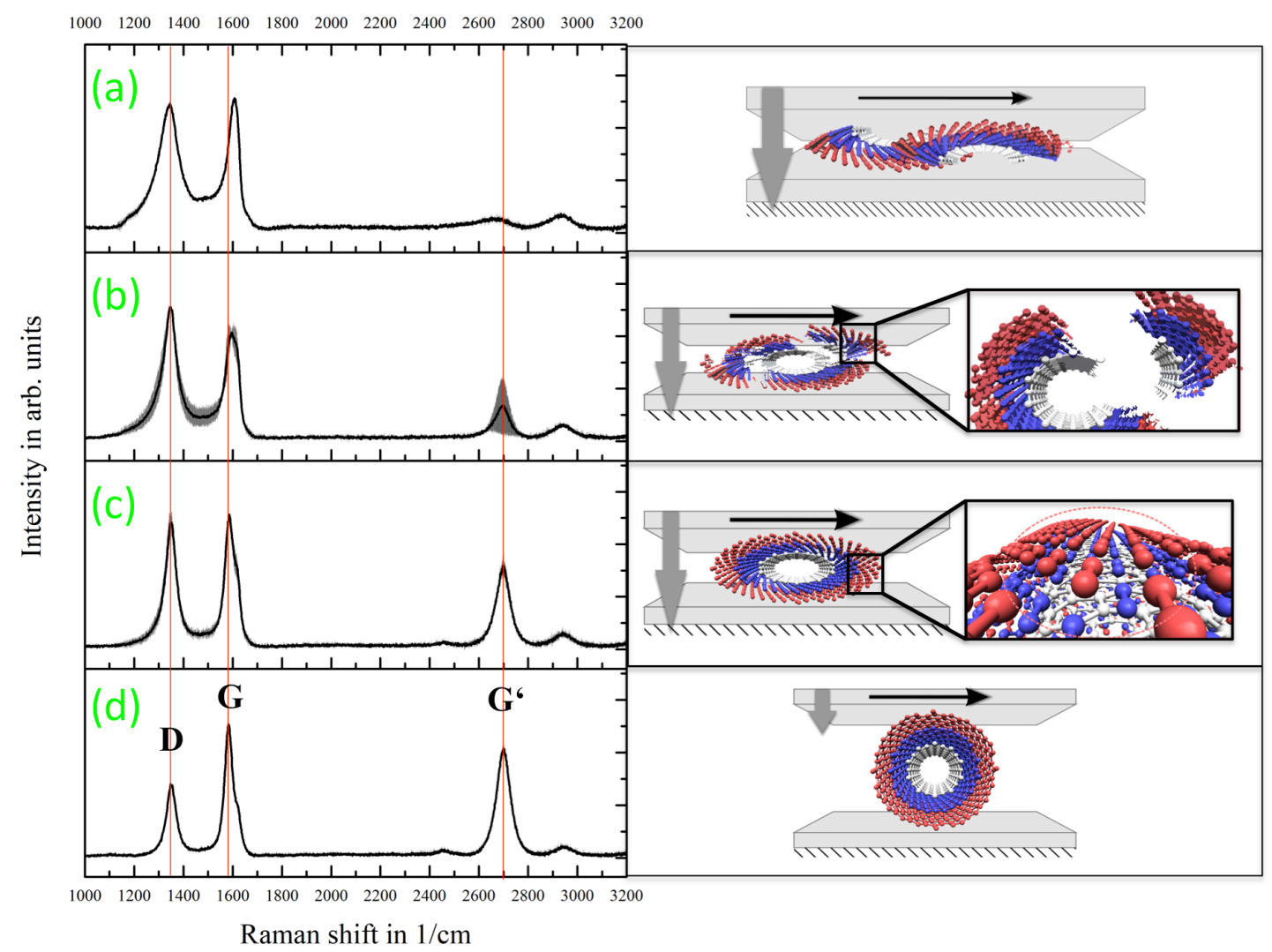

Fig 9: Raman spectroscopy analysis of the spots a-d in Fig. 8 indicating the characteristic bands for MWCNT. Each spectrum was recorded three times, and the mean value with the standard deviation are plotted. For each spectrum, a schematic is added in order to visualize the interpretation of the Raman signal and to demonstrate the corresponding contact situation.

The first peak at $1350 \mathrm{~cm}^{-1}$ belongs to the D-band, which is formed due to the presence of defects in the MWCNT structure. For example, a defect can be a crystal boundary in polycrystalline graphite or simply dangling covalent bonds of the aromatic system [59,60]. At around $1580-1600 \mathrm{~cm}^{-1}$, the G-band is detected. The G-band describes the crystalline state of $\mathrm{sp}^{2}$-hybridized carbon structures [61]. Its center position $\left(\mathrm{X}_{\mathrm{CG}}\right)$ is used in a three-stage phenomenological model developed by Ferrari et al. [49], which analyses the transition from an ordered graphitic-like to an amorphous-like structure, thus quantifying the degradation process of such a highly crystalline structure as MWCNT. Finally, at around $2700 \mathrm{~cm}^{-1}$, the G'-band corresponding to an overtone of the D-band is observed. The G'-band is very sensitive to carbonaceous impurities, providing a very close correlation to average purity values obtained by thermogravimetry [60].

From the first look at the spectra, it is obvious that, according to the measured spots on the worn tooth, the $\mathrm{X}_{\mathrm{CG}}$ is shifting from lower to higher wavenumbers as a function of the contact pressure growing from (d) to (a) in Fig. 8. This upshifting corresponds to a transient state of the MWCNTs (clustering of the affected graphitic structure) towards a nano-crystalline graphite [49]. In addition, the band intensities clearly change as a function of the measured spot (contact pressure). Raman spectra can be quantitatively evaluated by the normalized intensity ratios $D / G$ and $G^{\prime} / D$. Specifically, the $D / G$ ratio corresponds to the defect density and thus to the crystalline 
domain size, whereas the G'/D ratio can be correlated with the purity level of a graphitic material and is defined as the purity index $[61,62]$.

The corresponding intensity ratios of the recorded spectra as well as the G-band position can be found in Table 1. However, it should be kept in mind that these data present mean values of all MWCNTs measured at individual spots, where degraded MWCNTs can be blended with intact MWCNTs, generating an integral of structural state information.

Table 1: Intensity ratios of the $D, G$ and $G$ ' band as well as the G-band center position ( $\left.X_{C G}\right)$ as a function of the measurement location on the worn tooth according to Fig. 8.

\begin{tabular}{|c|c|c|c|}
\hline Position & $\mathbf{I}_{\mathbf{D}} / \mathbf{I}_{\mathbf{G}}$ & $\mathbf{I}_{\mathbf{G}}, \mathbf{I}_{\mathbf{D}}$ & $\mathbf{X}_{\mathbf{C G}}$ in $\mathbf{c m}^{-1}$ \\
\hline (a) & 0.96 & 0.11 & 1601 \\
\hline (b) & 1.23 & 0.26 & 1589 \\
\hline (c) & 0.94 & 0.65 & 1586 \\
\hline (d) & 0.55 & 1.48 & 1584 \\
\hline
\end{tabular}

Comparing the data in Table 1, it is clearly seen that the defect density increases from (d) to (b) from 0.55 to 1.23 and slightly decreases again for (a). The purity index significantly drops from (d) to (a) with the $\mathrm{X}_{\mathrm{CG}}$ wavenumber increasing from $1584 \mathrm{~cm}^{-1}$ to $1601 \mathrm{~cm}^{-1}$. According to the amorphisation trajectory model by Ferrari et al. [49], this corresponds to the structural amorphisation of the MWCNTs in the sliding contact. For spot (d), the MWCNTs are in pristine, highly ordered and graphitic condition, which also indicates that they are practically not stressed and can move freely. With increasing contact pressure, the MWCNTs are deformed, creating high stresses at the outer shells of the MWCNT structure, which can result in breaking of individual covalent bonds and thus higher defect density (see Table 1 (c) and Fig. 9 (c, b)). Moving towards the main contact zone, the MWCNT structures start to delaminate and nanocrystalline graphitic flakes are formed, as the $\mathrm{X}_{\mathrm{CG}}$ wavenumber reaches almost $1600 \mathrm{~cm}^{-1}$. The third body layer here consists of a mixture between the damaged MWCNTs and stacked graphene layers. Finally, at spot (a), the remaining MWCNT coating is fully degraded to nanocrystalline graphitic flakes and nearly no intact MWCNTs can be found anymore. The defect density index decreases again, which can be correlated with the second stage of amorphisation due to the further decreasing purity index [49].

When the MWCNT agglomerates found in the cavities of the worn composite material are analyzed within area 3, the spectrum in Fig. 10 is obtained. 


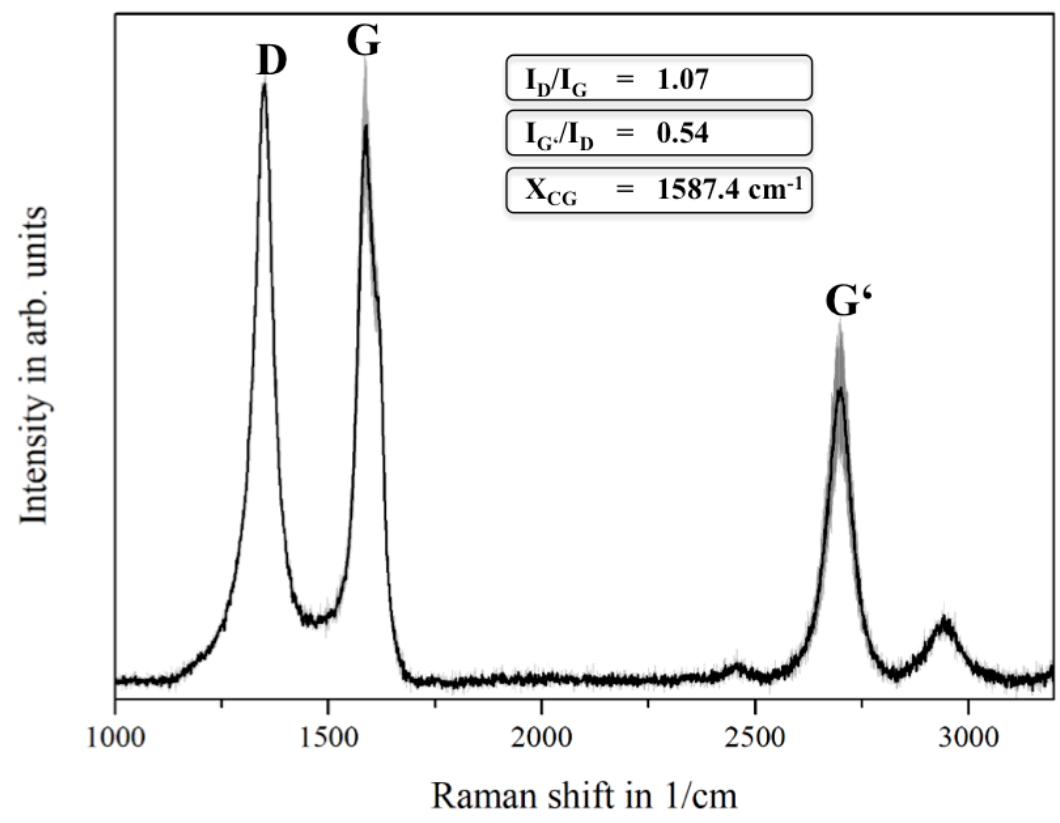

Fig 10: Raman spectrum of the MWCNTs found in the surface cavities within the worn area of the composite material in area 3 (according to Fig. 9). The intensity ratios as well as the $X_{C G}$ wavenumber are included.

The spectrum and thus the defect density, the purity index as well as the $\mathrm{X}_{\mathrm{CG}}$ wavenumber of the MWCNTs found in the surface cavities in area 3 are very similar to these found in spot (c) (see Fig. 9 and Table 1). This means that the MWCNTs in the cavities are only slightly degraded and can be dragged into the contact to enhance lubrication. Taking into account that the Raman signal consists of the superposition of the signal generated by the MWCNTs that have already been in contact and the MWCNTs that are still stored in the cavities of the composite, it is reasonable to assume that the stored MWCNTs are still close to their pristine condition. Additionally, as the crystalline graphite has already been formed in the contact by the degraded MWCNTs, the pristine MWCNTs can slide or roll over these graphite layers depending on the individual contact situation. This possibility has been discussed in the work of Falvo et al. [21] studying the rolling and sliding mechanisms of MWCNTs on graphite using an atomic force microscope. However, based on the recorded COF, the dominant lubrication mechanism of the presented system is certainly a mixture of the sliding MWCNTs and a graphite-based lubrication.

Finally, it is summarized that the MWCNTs from the cavities of the composite material are gradually brought into the contact, thus permanently lubricating the system. The steady state frictional behavior of the composite as well as the coated composite is dominated by the constant supply of the MWCNTs stored in the cavities of the composite material. However, a surface coating combined with laser texturing is capable to reduce the wear rate during the running-in of the system by a factor of 1.6 compared to the uncoated composite material. This can be explained by a more efficient surface separation by the MWCNTs in the coated case and by the capability of the surface depressions to supply the contact area with a larger amount of solid lubricant compared to the composite cavities. The wear reduction reaches similar values as for the uncoated composite as soon as all of the coating and laser structures are removed. Only by combining the MWCNT coating with the MWCNT-reinforced composite, could the lubrication mechanism of the MWCNTs be understood in detail. 


\section{Conclusions}

Here we report on the tribological behavior of an integral self-lubricating system under conformal contact conditions. The tests were carried out in a custom-built ring-on-block tribometer. We show that when combining a self-lubricating composite with an optimized solid-lubricant coating and a regular topography, improved selflubricating effects are obtained. This system shows a maximum 4-fold reduction in the coefficient of friction and a 115 -fold reduction in the wear rate compared to the reference state. Additionally, by performing a Raman spectroscopic characterization, we were able to evaluate the structural state of the solid lubricant throughout the generated pressure gradient, presenting a four-stage degradation model. Derived from this, it is possible to understand the lubrication mechanism of the MWCNTs and relate it to a transition from highly crystalline MWCNTs towards graphitic nano-clusters. The MWCNTs found in the cavities of the reinforced composite are close to their pristine state and are gradually brought into the contact, providing efficient lubrication throughout the lifetime of the composite material. The dominant lubrication mechanism is a mixture between the sliding MWCNTs and a graphite-based lubrication. Our results highlight the suitability of the proposed integrated solution as a promising approach for self-lubricating surfaces subjected to unidirectional sliding.

\section{Acknowledgements}

The present work is supported by funding from the Deutsche Forschungsgemeinschaft (DFG, project: MU 959/38-1 and SU 911/1-1). L. R., S.S., and F. M. wish to acknowledge the EFRE Funds of the European Commission for support of activities within the AME-Lab project. Prof. Dr. Volker Presser is acknowledged for providing the possibility to use Raman spectroscopy. This work was supported by the CREATe-Network Project, Horizon 2020 of the European Commission (RISE Project No. 644013). The authors further would like to thank Prof. Claudia A. Carrasco and Christopher Salvo for their help in processing the composite samples.

\section{Competing interests}

The authors declare no competing interests.

\section{References}

[1] H.K.D.H. Bhadeshia, Steels for bearings, Prog. Mater. Sci. $57 \quad$ (2012) $268-435$. doi:10.1016/j.pmatsci.2011.06.002.

[2] C. Gachot, A. Rosenkranz, L. Reinert, E. Ramos-Moore, N. Souza, M.H. Müser, F. Mücklich, Dry Friction Between Laser-Patterned Surfaces: Role of Alignment, Structural Wavelength and Surface Chemistry, Tribol. Lett. 9 (2013) 193-202. doi:10.1007/s11249-012-0057-y.

[3] A. Rosenkranz, L. Reinert, C. Gachot, F. Mücklich, Alignment and wear debris effects between laserpatterned steel surfaces under dry sliding conditions, Wear. (2014). doi:10.1016/j.wear.2014.06.016.

[4] M.M. Khonsari, E.R. Booser, Applied Tribology - Bearing design and lubrication, 2017.

[5] C. Donnet, A. Erdemir, Solid Lubricant Coatings: Recent Developments and Future Trends, Tribol. Lett. 17 (2004) 389-397. doi: 1023-8883/04/1000-0389/0

[6] S.M. Aouadi, H. Gao, A. Martine, T.W. Scharf, C. Muratore, Lubricious oxide coatings for extreme temperature applications: A review, Surf. Coatings Technol. 257 (2014) 266-277. doi: 10.1016/j.surfcoat.2014.05.064 
[7] D. Berman, A. Erdemir, A. V. Sumant, Graphene: A new emerging lubricant, Mater. Today. 17 (2014) 31-42. doi:10.1016/j.mattod.2013.12.003.

[8] A. Hirata, N. Yoshioka, Sliding friction properties of carbon nanotube coatings deposited by microwave plasma chemical vapor deposition, Tribol. Int. 37 (2004) 893-898. doi:10.1016/j.triboint.2004.07.005.

[9] L. Reinert, S. Suárez, A. Rosenkranz, Tribo-Mechanisms of Carbon Nanotubes: Friction and Wear Behavior of CNT-Reinforced Nickel Matrix Composites and CNT-Coated Bulk Nickel, Lubricants. 4 (2016) 11. doi:10.3390/lubricants4020011.

[10] L. Reinert, F. Lasserre, C. Gachot, P. Grützmacher, T. MacLucas, N. Souza, F. Mücklich, S. Suarez, Long-lasting solid lubrication by CNT-coated patterned surfaces, Sci. Rep. 7 (2017) doi: $10.1038 /$ srep42873.

[11] T.W. Scharf, A. Neira, J.Y. Hwang, J. Tiley, R. Banerjee, Self-lubricating carbon nanotube reinforced nickel matrix composites, J. Appl. Phys. 106 (2009). doi:10.1063/1.3158360.

[12] K.T. Kim, S. Il Cha, S.H. Hong, Hardness and wear resistance of carbon nanotube reinforced Cu matrix nanocomposites, Mater. Sci. Eng. A. 449-451 (2007) 46-50. doi:10.1016/j.msea.2006.02.310.

[13] X.H. Chen, J. Peng, F. Deng, J. Wang, W. Li, Tribological behavior of carbon nanotubes — reinforced nickel matrix composite coatings, J. Mater. Sci. Lett. 20 (2001) 2057-2060.

[14] X.H. Chen, C.S. Chen, H.N. Xiao, H.B. Liu, L.P. Zhou, S.L. Li, G. Zhang, Dry friction and wear characteristics of nickel/carbon nanotube electroless composite deposits, Tribol. Int. 39 (2006) 22-28. doi:10.1016/j.triboint.2004.11.008.

[15] D.K. Singh, P.K. Iyer, P.K. Giri, Diameter dependence of oxidative stability in multiwalled carbon nanotubes: Role of defects and effect of vacuum annealing, J. Appl. Phys. 108 (2010). doi:10.1063/1.3491022.

[16] K. Miyoshi, K.W.S. Jr., R.L. Vander Wal, R. Andrews, A. Sayir, Solid lubrication by multiwalled carbon nanotubes in air and in vacuum, Tribol. Lett. 19 (2005) 191-201. doi:10.1007/s11249-005-61464.

[17] L. Reinert, S. Schütz, S. Suarez, F. Mücklich, Influence of Surface Roughness on the Lubrication Effect of Carbon Nanoparticle-Coated Steel Surfaces, Tribol. Lett. 66 (2018). doi:10.1007/s11249-018-1001-6.

[18] S. Iijima, Helical microtubules of graphitic carbon, Nature. 354 (1991) 56-58. doi: 10.1038/354056a0

[19] Y. Gogotsi, V. Presser, Carbon Nanomaterials, 2014. CRC press. ISBN: 978-1-4665-0242-0

[20] M.F.L. De Volder, S.H. Tawfick, R.H. Baughman, A.J. Hart, Carbon nanotubes: present and future commercial applications., Science. 339 (2013) 535-9. doi:10.1126/science.1222453.

[21] M.R. Falvo, R.M.T. Ii, A. Helser, V. Chi, Nanometre-scale rolling and sliding of carbon nanotubes, Nature. 397 (1999) 1-3. doi: 10.1038/16662

[22] P.L. Dickrell, S.B. Sinnott, D.W. Hahn, N.R. Raravikar, L.S. Schadler, P.M. Ajayan, W.G. Sawyer, Frictional anisotropy of oriented carbon nanotube surfaces, Tribol. Lett. 18 (2005) 59-62. doi:10.1007/s11249-004-1752-0.

[23] P.L. Dickrell, S.K. Pal, G.R. Bourne, C. Muratore, A.A. Voevodin, P.M. Ajayan, L.S. Schadler, W.G. Sawyer, Tunable friction behavior of oriented carbon nanotube films, Tribol. Lett. 24 (2006) 85-90. doi:10.1007/s11249-006-9162-0.

[24] B. Ni, S.B. Sinnott, Tribological properties of carbon nanotube bundles predicted from atomistic simulations, Surf. Sci. 487 (2001) 87-96. doi:10.1016/S0039-6028(01)01073-1.

[25] J.M. Martin, N. Ohmae, Nanolubricants, 2008. John Wiley \& Sons Ltd, ISBN: 978-0-470-06552-5

[26] R. Greenberg, G. Halperin, I. Etsion, R. Tenne, The effect of WS2 nanoparticles on friction reduction in various lubrication regimes, Tribol. $\quad$ Lett. $17 \quad$ (2004) 179-186. doi:10.1023/B:TRIL.0000032443.95697.1d.

[27] J.J. Hu, S.H. Jo, Z.F. Ren, A. Voevodin, J.S. Zabinski, Tribological behavior and graphitization of 
carbon nanotubes grown on 440C stainless steel, Tribol. Lett. 19 (2005) 119-125. doi:10.1007/s11249005-5091-6.

[28] A. Dorri Moghadam, E. Omrani, P.L. Menezes, P.K. Rohatgi, Mechanical and tribological properties of self-lubricating metal matrix nanocomposites reinforced by carbon nanotubes (CNTs) and graphene - A review, Compos. Part B Eng. 77 (2015) 402-420. doi:10.1016/j.compositesb.2015.03.014.

[29] F. Colonna, A. Fasolino, E.J. Meijer, Graphitization of single-wall nanotube bundles at extreme conditions: Collapse or coalescence route, Phys. Rev. B. 88 (2013) 165416. doi:10.1103/PhysRevB.88.165416.

[30] S. Suárez, A. Rosenkranz, C. Gachot, F. Mücklich, Enhanced tribological properties of MWCNT/Ni bulk composites - Influence of processing on friction and wear behaviour, Carbon 66 (2014) 164-171. doi:10.1016/j.carbon.2013.08.054.

[31] S.V. Prasad, R. Asthana, Aluminum Metal-Matrix Composites for Automotive Applications: Tribological Considerations, Tribol. $\quad$ Lett. $\quad 17 \quad$ (2004) 445-453. doi:10.1023/B:TRIL.0000044492.91991.f3.

[32] M. Rosso, Ceramic and metal matrix composites: Routes and properties, J. Mater. Process. Technol. 175 (2006) 364-375. doi:10.1016/j.jmatprotec.2005.04.038.

[33] D. Miracle, Metal matrix composites - From science to technological significance, Compos. Sci. Technol. 65 (2005) 2526-2540. doi:10.1016/j.compscitech.2005.05.027.

[34] I.M. Hutchings, Tribological properties of metal matrix composites, Mater. Sci. Technol. 10 (1994). doi: 10.1179/mst.1994.10.6.513

[35] L. Reinert, S. Suarez, T. Müller, F. Mücklich, Carbon Nanoparticle-Reinforced Metal Matrix Composites: Microstructural Tailoring and Predictive Modeling, Adv. Eng. Mater. 19 (2017) 1-6. doi:10.1002/adem.201600750.

[36] L. Reinert, M. Zeiger, S. Suarez, V. Presser, F. Mücklich, Dispersion analysis of carbon nanotubes, carbon onions, and nanodiamonds for their application as reinforcement phase in nickel metal matrix composites, RSC Adv. 5 (2015) 95149-95159. doi:10.1039/C5RA14310A.

[37] R.A. Shahani, T.W. Clyne, Recrystallization in fibrous and particulate metal matrix composites, Mater. Sci. Eng. A. 135 (1991) 281-285. doi: 10.1016/0921-5093(91)90576-9

[38] L. Rapoport, A. Moshkovich, V. Perfilyev, I. Lapsker, G. Halperin, Y. Itovich, I. Etsion, Friction and wear of MoS2 films on laser textured steel surfaces, Surf. Coatings Technol. 202 (2008) 3332-3340. doi:10.1016/j.surfcoat.2007.12.009.

[39] A.A. Voevodin, J.S. Zabinski, Laser surface texturing for adaptive solid lubrication, Wear. 261 (2006) 1285-1292. doi:10.1016/j.wear.2006.03.013.

[40] L. Rapoport, A. Moshkovich, V. Perfilyev, A. Gedanken, Y. Koltypin, E. Sominski, G. Halperin, I. Etsion, Wear life and adhesion of solid lubricant films on laser-textured steel surfaces, Wear. 267 (2009) 1203-1207. doi:10.1016/j.wear.2009.01.053.

[41] J. Deng, Y. Lian, Z. Wu, Y. Xing, Performance of femtosecond laser-textured cutting tools deposited with WS2 solid lubricant coatings, Surf. Coatings Technol. 222 (2013) 135-143. doi:10.1016/j.surfcoat.2013.02.015.

[42] S. Suarez, L. Reinert, M. Zeiger, V. Presser, P. Miska, F. Müller, F. Mücklich, In-situ nanodiamond to onion-like carbon transformation in metal matrix composites, Carbon 129 (2018) 631-636. doi: 10.1016/j.carbon.2017.12.072

[43] S. Suarez, F. Lasserre, F. Mücklich, Mechanical properties of MWNT/Ni bulk composites: Influence of the microstructural refinement on the hardness, Mater. Sci. Eng. A. 587 (2013) 381-386. doi:10.1016/j.msea.2013.08.058.

[44] A. Lasagni, M. D’Alessandria, R. Giovanelli, F. Mücklich, Advanced design of periodical architectures in bulk metals by means of Laser Interference Metallurgy, Appl. Surf. Sci. 254 (2007) 930-936. 
doi:10.1016/j.apsusc.2007.08.010.

[45] B. Raillard, F. Mücklich, Ablation effects of femtosecond laser functionalization on surfaces, Laser Surf. Eng. Process. Appl. 207 (2014) 565-581. doi:10.1016/B978-1-78242-074-3.00024-6.

[46] K.H. Leitz, B. Redlingshöer, Y. Reg, A. Otto, M. Schmidt, Metal ablation with short and ultrashort laser pulses, Phys. Procedia. 12 (2011) 230-238. doi:10.1016/j.phpro.2011.03.128.

[47] A.R. Boccaccini, J. Cho, J. a. Roether, B.J.C. Thomas, E. Jane Minay, M.S.P. Shaffer, Electrophoretic deposition of carbon nanotubes, Carbon 44 (2006) 3149-3160. doi:10.1016/j.carbon.2006.06.021.

[48] M.F. De Riccardis, D. Carbone, A. Rizzo, A novel method for preparing and characterizing alcoholic EPD suspensions., J. Colloid Interface Sci. 307 (2007) 109-15. doi:10.1016/j.jcis.2006.10.037.

[49] A. Ferrari, J. Robertson, Resonant Raman spectroscopy of disordered, amorphous, and diamondlike carbon, Phys. Rev. B. 64 (2001) 75414. doi:10.1103/PhysRevB.64.075414.

[50] P.A. Manohar, M. Ferry, T. Chandra, Five Decades of the Zener Equation, ISIJ Int. 38 (1998) 913-924. doi: 10.2355 /isijinternational.38.913

[51] N. Hansen, Hall-Petch relation and boundary strengthening, Scr. Mater. 51 (2004) 801-806. doi:10.1016/j.scriptamat.2004.06.002.

[52] A. Sanaty-Zadeh, Comparison between current models for the strength of particulate-reinforced metal matrix nanocomposites with emphasis on consideration of Hall-Petch effect, Mater. Sci. Eng. A. 531 (2012) 112-118. doi:10.1016/j.msea.2011.10.043.

[53] R. Mishra, B. Basu, R. Balasubramaniam, Effect of grain size on the tribological behavior of nanocrystalline nickel, Mater. Sci. Eng. A. 373 (2004) 370-373. doi:10.1016/j.msea.2003.09.107.

[54] P.J. Blau, On the nature of running-in, Tribol. Int. 38 (2005) 1007-1012. doi:10.1016/j.triboint.2005.07.020.

[55] I. Hutchings, P. Shipway, Tribology: Friction and Wear of Engineering Materials, ButterworthHeinemann, Elsevier, 2017. ISBN: 978-0-08-100910-9

[56] M. Shafiei, A.T. Alpas, Friction and Wear Mechanisms of Nanocrystalline Nickel in Ambient and Inert Atmospheres, Metall. Mater. Trans. A. 38 (2007) 1621-1631. doi:10.1007/s11661-007-9157-y.

[57] R.K. Singh Raman, A.S. Khanna, R.K. Tiwari, J.B. Gnanamoorthy, Influence of grain size on the oxidation resistance of 2 1/4 Cr-1Mo steel, Oxid. Met. 37 (1992) 1-12. doi:10.1007/BF00665627.

[58] M. Varenberg, Towards a unified classification of wear, Friction. 1 (2013) 333-340. doi:10.1007/s40544-013-0027-x.

[59] Y. Liu, R.L. Vander Wal, V.N. Khabashesku, Functionalization of Carbon Nano-onions by Direct Fluorination, Chem. Mater. 19 (2007) 778-786. doi: 10.1021/cm062177j

[60] J.H. Lehman, M. Terrones, E. Mansfield, K.E. Hurst, V. Meunier, Evaluating the characteristics of multiwall carbon nanotubes, Carbon 49 (2011) 2581-2602. doi:10.1016/j.carbon.2011.03.028.

[61] R.A. DiLeo, B.J. Landi, R.P. Raffaelle, Purity assessment of multiwalled carbon nanotubes by Raman spectroscopy, J. Appl. Phys. 101 (2007). doi:10.1063/1.2712152.

[62] F. Tuinstra, J.L. Koenig, Raman Spectrum of Graphite, J. Chem. Phys. 53 (1970) 1126-1130. doi:10.1063/1.1674108. 